American Journal of Pharmaceutical Education 2019; 83 (9) Article 7338.

\title{
RESEARCH
}

\section{Potency Analyses Provide Insight Into Student Aseptic Compounding Technique Errors}

\author{
Rebecca K. Lee, PharmD, Robert P. Shrewsbury, PhD \\ Eshelman School of Pharmacy, University of North Carolina at Chapel Hill, Chapel Hill, North Carolina \\ Submitted August 19, 2018; accepted February 21, 2019; published November 2019.
}

\begin{abstract}
Objective. To determine whether direct observational scores were predictive of the potency of pharmacy students' compounded sterile preparations (CSPs) and to identify any misunderstandings students had regarding individual aseptic technique steps.

Methods. P1 students performed aseptic techniques during three observational encounters separated by two weeks. Students' performances were evaluated using an observation-based rubric and were subject to potency analysis. The encounters were transferring a drug solution from a vial, an ampule, and a reconstituted powder to intravenous (IV) bags.

Results. The mean potency of the diphenhydramine (vial) and lidocaine (ampule) met the $\pm 10 \%$ goal of expected potency. These results were significantly different from those of the ampicillin (reconstitution) encounter, which was outside the goal. The percentage of students meeting the potency goal was $59.3 \%$ for the diphenhydramine, $80.3 \%$ for the lidocaine, and $50.4 \%$ for the ampicillin encounters. The observation scores were significantly different between all three encounters. There were no correlations between the observational scores and the potency for any encounter regardless of whether or not the student met the goal potency. Although their observation scores were acceptable, up to $50 \%$ of students did not meet the potency goal for each of the three encounters.

Conclusion. The potency data provided the critical insight that P1 students were not adequately trained to account for pressurization when manipulating vials using aseptic compounding processes. The results suggest that both observation scores and potency analysis should be part of an overall assessment of student ability to compound sterile preparations.
\end{abstract}

Keywords: potency analysis, aseptic technique, compounding, observational evaluation

\section{INTRODUCTION}

Pharmacy compounding is defined as the art and science of preparing personalized medications for patients. ${ }^{1}$ Compounding allows pharmacists to work with patients and prescribers to customize a medication and meet a patient's specific need. The recognition of the importance of compounding in schools of pharmacy has been highlighted by the Accreditation Council for Pharmacy Education (ACPE), American Association of Colleges of Pharmacy (AACP), and the National Association of Boards of Pharmacy (NABP). ${ }^{2-4}$ However, none of their standards and requirements provide a pedagogical methodology that should be used to teach compounding skills in the classroom or the cleanroom. ${ }^{5}$

Pharmaceutical compounding intersects with patient care in both nonsterile and sterile preparations. In the arena

Corresponding Author: Robert P. Shrewsbury, Eshelman School of Pharmacy, University of North Carolina at Chapel Hill, 301 Pharmacy Ln., Chapel Hill, NC 27599-7574. Tel: 919-962-0093. Email: bob_shrewsbury@unc.edu. of sterile compounding, adverse events, including death, have occurred when sterile compounds are contaminated with microbial organisms. ${ }^{6,7}$ The United States Pharmacopeia (USP) sets standards for sterile compounding (USP General Chapter <797>, https://www.usp.org/ compounding/general-chapter-797), and most state boards of pharmacy require pharmacists to comply with these standards. As such, providing instruction in sterile compounding is an essential responsibility of all schools of pharmacy.

The scope, frequency, timing, and methods by which pharmacy schools implement curricula on aseptic technique are specific to each program. ${ }^{8}$ Surveys of various schools of pharmacy have reported the frequency and depth of compounded sterile preparation education. ${ }^{9-12}$ Hellmus and colleagues found that all of the 48 schools responding to their survey included some type of instruction on compounded sterile preparations (CSPs). ${ }^{11}$ Only $70 \%$ allowed students to compound on their own (rather than in groups or not at all), and only $21 \%$ offered a 


\section{American Journal of Pharmaceutical Education 2019; 83 (9) Article 7338.}

standalone course on this topic. Students having experience in sterile compounding prior to entering school and students undergoing repeated assessment in school during a short period of time have been reported to show improved aseptic compounding skills. ${ }^{5,13-16}$ As a corollary to experience and repeated testing within a small period of time, the issue of how frequently aseptic technique training should be included within an entire curriculum and the optimal points to include such training have also been discussed. $^{8,17}$

Sterile compounding courses are often short in duration and expensive to conduct which leads to inadequate training of pharmacy students in the use of aseptic techniques. Consequently, most sterile compounding instruction is limited to one semester and commonly taught in the P1 year. This creates the possibility that upon entering the workforce, graduates are three years removed from their aseptic technique training and may no longer possess the basic knowledge or skills. Ely and Birnie found that students did not retain nonsterile compounding skills for more than one year. ${ }^{18}$ Numerous course designs and evaluation schemes have attempted to maximize compounding instruction outcomes. ${ }^{5,19}$ Newer technologies have also made use of simulations to optimize instruction time. Penguin Innovations (West Lafayette, IN) is developing a virtual interactive cleanroom simulation as an instructional additive or alternative for students to become familiar with the complexities of a cleanroom environment and to gain an overview of aseptic manipulation techniques. ${ }^{20,21}$ Table 1 displays a compilation of published references for assessing sterile compounding instruction. $^{8,12-17,19-34}$

Both course design and assessment criteria are important influences on the outcomes students achieve in a sterile compounding course. In the actual compounding of CSPs, there are three central factors that must be controlled to minimize microbial contamination: engineering controls, personnel control, and process control. Of the three factors, schools of pharmacy primarily focus on the teaching of process control, ie, aseptic techniques. Aseptic compounding techniques are typically evaluated by a variety of methods because educators like to address the differences in student learning preferences and needs. Direct observation of students' aseptic techniques during the compounding process is a common evaluation method. However, direct observation only provides a partial evaluation of all of the aspects of sterile compounding, and is only useful if the observations are done one-on-one by personnel who are competent in the preparation and evaluation of compounded sterile preparations (CSPs).

One methodology for assessing students' compounding competency of CSPs that is rarely described in the pharmacy education literature is the quantitative analysis of the potency of the active pharmaceutical ingredient (API). ${ }^{35}$ Potency analysis is an objective measure of competency and does not require additional expenditures for compounding supplies. Furthermore, if students perform the analysis themselves, such an assessment requires negligible additional faculty time. Pharmaceutical analysis is required from a regulatory standpoint when assigning beyond-use dates (BUDs) for CSPs that are longer than the default dates given in USP $<797>$. However, two factors might limit a school-wide adoption of such methodology: first, the initial cost of the instrumentation; and second, faculty or instructor expertise in carrying out of valid pharmaceutical analysis methods.

A survey of compounding curricula in schools of pharmacy found that most survey respondents cited direct observation as their primary assessment approach, while only a small percentage (8\%) of institutions used a quantitative method to evaluate student preparations. ${ }^{36}$ Only one study has been published where potency analysis was part of an assessment scheme that also involved media fill analysis. ${ }^{17}$ Direct observation may be a good surrogate method of assessment for schools that do not have the ability to carry out analyses of student preparations, as observation does provide general feedback to students about the commonly missed or incorrectly performed manipulations required in aseptic techniques.

At the University of North Carolina Eshelman School of Pharmacy, the assessment of students' compounding abilities using a multitude of assessment tools has remained a top priority in the curriculum for several years. One of the predominant assessment methods has been to determine the preparations' potencies by

Table 1. Assessment Methods Used in Schools of Pharmacy to Evaluate Aseptic Technique

\begin{tabular}{lr}
\hline Assessment Method & References \\
\hline Grading rubrics & $12,13-16,19$ \\
Direct instructor observation & $12,13-17,19$ \\
Improvement in media fill test pass rates & $13-16$ \\
Online teaching media & $8,20-21$ \\
Compounding practice protocols with & 8 \\
$\quad$ instructor feedback & 8 \\
Terminal assessment methods & 22,23 \\
Objective structured assessment of technical & \\
$\quad$ skills checklist & 19 \\
Flexible learning via online video review & $24-27$ \\
Podcast & $28-32$ \\
Lecture video & $17,19-21$ \\
Topic video, demonstration video & 33,34 \\
Student self-reflection after compounding & \\
\hline
\end{tabular}




\section{American Journal of Pharmaceutical Education 2019; 83 (9) Article 7338.}

pharmaceutical analysis. ${ }^{1,37}$ The analyses have provided profound insight into pharmacy students' abilities to accurately compound preparations. The analytical work has also enhanced student understanding of the quality of compounded preparations and encouraged them to formulate better preparations. As concluded in a previous study by Jih and Shrewsbury, having students analyze their own preparations increased their self-confidence and their competence in their compounding ability. ${ }^{38}$

This study was undertaken to determine several answers to questions that are not currently reported in the pharmacy education literature. The first question we addressed was whether observational scores are good predictors of acceptable potency results. The second question was what percentage of students would successfully prepare a CSP within an acceptable potency range on the first attempt. The third question was whether support should be given to a recommendation that both observational scores and potency analysis be part of an overall assessment plan for pharmacy students compounding CSPs. The study was approved by the University of North Carolina Biomedical IRB Committee.

\section{METHODS}

First-professional year (P1) pharmacy students compounded three different sterile preparations during three separate observational encounters. The first encounter assessed proficiency in withdrawing and transferring $40 \mathrm{mg}$ of diphenhydramine from a $1 \mathrm{~mL}(50 \mathrm{mg} /$ $\mathrm{mL}$ ) vial into a $50-\mathrm{mL}$ normal saline (NS) intravenous (IV) bag. The second encounter occurred two weeks later and assessed student proficiency in breaking a $2 \mathrm{~mL} \mathrm{li-}$ docaine $(15 \mathrm{mg} / \mathrm{mL})$ ampule, withdrawing $30 \mathrm{mg}$ of lidocaine with a filter needle, switching to a 21 or 23 gauge needle, and injecting the contents into a $50 \mathrm{~mL}$ NS IV bag. The third encounter occurred two weeks following the second encounter and assessed the reconstitution of ampicillin $(125 \mathrm{mg} / \mathrm{vial})$ with $5 \mathrm{~mL}$ of $\mathrm{NS}$, followed by withdrawal and injection of $110 \mathrm{mg}$ of ampicillin into a 50 mL NS IV bag.

Prior to each observational encounter, students completed two in-class instruction sessions led by a teaching assistant (TA). In the first session, the TA taught proper aseptic techniques and an explanation of the packaging and devices to be used during the semester. In the second session, students practiced the aseptic techniques to be used specifically in the first encounter. Students were also given a copy of the observational rubric that would be used to assess their technique (Appendix 1). The observational rubric was modified after the first encounter to better characterize the techniques required for encounters two and three (Appendix 2). The TAs did not receive any specialized instruction on how to grade the students during each encounter. However, they were instructed to give either full credit or zero credit for each action item in the observational rubric. The majority of the TAs were licensed pharmacy residents from schools other than the Eshelman School of Pharmacy, with the remainder (three out of 12) being second- or third-year Eshelman School of Pharmacy students who demonstrated competency in the course during their first year of pharmacy school.

During each observational encounter, students were evaluated on their ability to interpret an IV order, gather and place supplies in the laminar airflow workstation (LAFW), and compound a sterile preparation using aseptic techniques within a suggested 15-minute time constraint. Garbing, hand hygiene, and cleaning of the LAFW were assessed previously and not included in these evaluations. Students were evaluated individually by a different TA from the one they had been assigned to for the semester. The TAs were not assessed for grading uniformity. Between encounters, students were given the opportunity to practice for the next encounter on their own time. Supplies were available during regular school hours for additional practice and the course instructor or TAs were available to provide further instruction.

Immediately following each observational encounter, students withdrew sufficient volume twice from their IV bag to produce two samples of $3 \mathrm{~mL}$ and placed the samples in methacrylate cuvettes. The samples were read on a spectrophotometer at the following wavelengths for each API: diphenhydramine (vial) at $270 \mathrm{~nm}$, lidocaine (ampule) at $275 \mathrm{~nm}$, ampicillin (reconstitution) at $265 \mathrm{~nm}$. Each student recorded the absorbance of both samples on a log sheet. A laboratory staff member calculated the potency of each sample using the appropriate linearity assay data. The average of the two potency determinations was calculated. The goal average potency was defined as $\pm 10 \%$ of intended concentration. The standard curves, which were prepared immediately prior to the evaluations, contained data points that matched the expected concentrations, and were corrected for the average overfill in a $50 \mathrm{~mL}$ normal saline IV bag (approximately $7 \mathrm{~mL}$ ).

The observational scores from the rubrics and the potency values from the students' self-analyses were organized in Excel by encounter and student name. All negative or zero potency values were excluded from further statistical analysis because a negative or zero value could indicate that no API was transferred into the normal saline bag or that the student incorrectly analyzed their preparation. In the entire study, this omission accounted for $2 \%$ of the total number of data pairs. The potency values 


\section{American Journal of Pharmaceutical Education 2019; 83 (9) Article 7338.}

and observational scores were matched per student, and a $z$ test for two means was used in all comparisons to determine significance as the variance of each population size was known and each population size was greater than 30 . A $p=.05$ was set as the level of significance.

\section{RESULTS}

Data were organized by type of observational encounter and by endpoint criteria. "All students" refers to all of the students who participated in the encounter that had a non-negative, nonzero potency value. "Students meeting potency endpoint" refers to students whose samples were within $\pm 10 \%$ of expected potency, which was the long-standing laboratory standard.

The descriptive statistics for potency data are shown in Table 2. The mean potency of all students for the diphenhydramine and lidocaine CSPs met the goal of $\pm 10 \%$ of expected potency. However, the mean potency for the ampicillin CSP fell below this mark. The mean potency of the students' diphenhydramine and lidocaine CSPs did not differ significantly from one another. However, the potencies of both the diphenhydramine and lidocaine CSPs differed significantly from that of the ampicillin CSP. This suggested that the ampicillin reconstitution encounter was relatively more difficult for students.

The percentages of students that compounded their preparations within the potency endpoint were $59.3 \%$ for the diphenhydramine (withdrawn from a vial), $80.3 \%$ for the lidocaine (withdrawn from an ampule), and 50.4\% for the ampicillin (reconstituted from a powder). There were no significant differences between the groups' averaged potencies. The standard deviation (SD) of the three encounters was the same order of magnitude, suggesting a "consistent" number of students might have experienced difficulties with these skills between each encounter. Both the kurtosis and skewness of the data improved in this group compared to that for all students, indicating a more normal distribution of potency values. There was also a substantial decrease in the range of potencies.

The descriptive statistics of the observational scores for each encounter are shown in Table 3. The number of observational results differed slightly from the number of potency results because some TAs returned the rubrics to students prior to the data collection. All possible mean comparisons for all students and students meeting the potency endpoint were significantly different. The standard deviations and ranges for both groups were similar in magnitude, which suggests that the variances were similar regardless of potency value. However, a trend towards improvement in the observational score was seen as students in both groups progressed throughout the encounters.

Table 4 shows the breakdown of points awarded to all students for the performance of each action item listed on the aseptic technique rubrics (Appendix 1 and Appendix 2). Of these items, action item 2, "Assembles necessary supplies; syringe and needle sizes are appropriate to task," had the lowest SD for all encounters, whereas, action item 6, "Withdraws contents of vial or

Table 2. Potency Results for All Encounters to Gain Insight Into Student Aseptic Technique Errors

\begin{tabular}{|c|c|c|c|}
\hline & Vial & Ampule & Reconstitution \\
\hline \multicolumn{4}{|l|}{ All students } \\
\hline Mean (SD) & $94.4(16.3)^{\mathrm{a}, \mathrm{c}}$ & $97.3(10.0)^{\mathrm{a}, \mathrm{b}}$ & $88.5(12.7)^{\mathrm{b}, \mathrm{c}}$ \\
\hline Kurtosis & 8.8 & 16.1 & 2.0 \\
\hline Skewness & -1.3 & -2.3 & -0.8 \\
\hline Range & $10.9-151.9$ & $30.8-120.5$ & $42.3-127.6$ \\
\hline \multicolumn{4}{|c|}{ Student meeting potency endpoint } \\
\hline Mean (SD) & $97.6(4.6)^{\mathrm{d}}$ & $98.4(4.3)$ & $97.3(4.9)$ \\
\hline $\mathrm{N}$ & 64 & 94 & 61 \\
\hline Percent & 59.3 & 80.3 & 50.4 \\
\hline Kurtosis & 0.05 & 0.04 & -0.61 \\
\hline Skewness & 0.41 & 0.53 & 0.50 \\
\hline
\end{tabular}


American Journal of Pharmaceutical Education 2019; 83 (9) Article 7338.

Table 3. Observational Scores for All Encounters to Gain Insight Into Student Aseptic Technique Errors

\begin{tabular}{lccc}
\hline & Vial & Ampule & Reconstitution \\
\hline All students & & & \\
$\quad$ Mean (SD) & $18.6(4.1)^{\mathrm{a}, \mathrm{c}}$ & $20.3(3.6)^{\mathrm{a}, \mathrm{b}}$ & $21.6(3.1)^{\mathrm{b}, \mathrm{c}}$ \\
Kurtosis & -0.61 & -0.61 & 0.1 \\
Skewness & -0.31 & -0.42 & -0.90 \\
Range & $8-25$ & $11-25$ & $13-25$ \\
& & & $22.0(3.2)^{\mathrm{e}, \mathrm{f}}$ \\
Students meeting potency endpoint & & $20.6(3.7)^{\mathrm{d}, \mathrm{e}}$ & -0.040 \\
$\quad$ Mean (SD) & $18.8(3.8)^{\mathrm{d}, \mathrm{f}}$ & -0.47 & -0.91 \\
Kurtosis & -0.74 & -0.58 & $13-25$ \\
$\quad$ Skewness & -0.24 & $11-25$ & \\
$\quad$ Range & $10-25$ & & \\
\hline
\end{tabular}

${ }^{a}$ Difference between vial and ampule encounters, $p=.0007$

${ }^{\mathrm{b}}$ Difference between ampule and reconstitution encounters, $p=.003$

${ }^{\mathrm{c}}$ Difference between vial and reconstitution encounters, $p<.0001$

${ }^{\mathrm{d}}$ Difference between vial and ampule encounters, $p=.0025$

${ }^{\mathrm{e}}$ Difference between ampule and reconstitution encounters, $p=.015$

${ }^{\mathrm{f}}$ Difference between vial and reconstitution encounters, $p<.001$

glass ampule appropriately," had the highest standard deviation for all encounters. Action item 2 was likely the least difficult skill to perform, while action item 6 was likely the most difficult. Action item 6 may correspond best with potency values as this action item was the only point where API volume was manipulated. The same results were seen with the observational data of the students meeting the potency endpoint, ie, action item 2 had the lowest SD and action item 6 had the highest SD (data not shown).

Correlations of observational scores and potency values were constructed in each encounter to determine if a relationship existed such that the students with the higher observational scores also compounded preparations that met the potency endpoint. The correlation plots for all students and students meeting the potency endpoint are shown in Figures 1 and 2, respectively. The correlation equations of fit and the corresponding $\mathrm{R}^{2}$ value are shown in Table 5. There was no correlation between the observational score and the measured potency in any encounter for either group. Correlation coefficients suggested that less than $10 \%$ of the variation in the measured potency could be attributed to the observational score.

\section{DISCUSSION}

The ability to work in a LAFW using aseptic techniques is a fundamental skill that pharmacy students must have, whether they compound CSPs themselves or evaluate someone else's compounding procedures. Direct observation is the most common evaluation tool used to assess students. One methodology rarely used in the direct assessment of a student's compounding proficiency is the quantitative determination of the API's potency. A central objective of this study was to determine if sample analysis provided better insights into the students' ability to compound acceptable CSPs.

The results showed a lack of correlation between the measured potency and the observational values. One consideration that may have overshadowed the correlation predictions was the use of manufactured products. The concentrations of the APIs in commercially available products meet USP standards: the diphenhydramine hydrochloride injection and ampicillin for injection were to be $\pm 10 \%$ of label, and the lidocaine hydrochloride injection should have been $\pm 5 \%$. Varying the potency values by these percentages to simulate the possible contribution variability in the API concentration did not improve the lack of correlations between the measured potency and observational values.

The other explanation that would account for the potency variability was a failure of the student to withdraw the correct volume of solution from the vial or ampule before transferring the drug solution to the IV bag. This would occur if the student withdrew the incorrect volume or if the volume was correct based on the placement of the plunger within the syringe barrel, but the student had not adequately removed the air bubbles. With the ampicillin reconstitution encounter, variability could have occurred at two points: if the wrong volume of diluent was added to the vial to be reconstituted; and if the wrong volume of reconstituted solution was removed from the vial before transferring the drug solution to the IV bag. 
American Journal of Pharmaceutical Education 2019; 83 (9) Article 7338.

Also, students may have had difficulties knowing how to correctly determine (by calculation) the volume of solution to be withdrawn from the vial. The diphenhydramine withdrawal and ampicillin reconstitution encounters were designed such that the students did not withdraw the entire vial contents for the preparation. The lidocaine encounter required the student to withdraw the total volume contained in the ampule. Even for students who could not determine the correct volume to withdraw from the ampule, they may have known to withdraw approximately all of the contents of the ampule into their syringe. It may be prudent to consider a more complicated medication order for the ampule encounter. Obtaining student feedback on the difficulties they had with each encounter would be helpful to elucidate this point.

In each encounter, action item 6 had the greatest variability (ie, SD) of all of the observational scores. Consideration was given to the possibility that action item 6 might directly correlate with potency variability. The difficulty with such a correlation analysis in this study was that action item 6 had only two possible values: no score (ie, 0 ) or the maximum score for that item. Therefore, the scale of the observational scores was limited compared to the scale in potency values, and a correlation would be of limited validity. Thus, the mean potency for the two possible observational scores was determined for both groups (ie, all students and students meeting the potency endpoint) in all three encounters. In the group of all students, the mean potency values for the diphenhydramine and lidocaine encounters were not significantly different regardless of the respective action item 6 score. However, the mean potency values for the diphenhydramine and lidocaine encounters were different from the ampicillin reconstitution encounter for both possible action item 6 scores. This was the same pattern as seen for this group using the total observational score instead of action item 6 . For the students meeting the potency endpoint, the only statistical difference between the two observational scores was found in the ampicillin encounter. This was not the pattern seen when using the total observational score. This result suggested that action item 6 may be a key indicator in the students' inability to obtain the correct volume of drug solution to transfer to the IV bag during the ampicillin reconstitution encounter. However, which of the possible scenarios the student failed to execute correctly cannot be determined from this result.

Action item 6 required the student to "withdraw the contents of the vial or ampule appropriately," which again confirmed that this one procedural step was the most critical step of the entire process if the goal was to have an acceptably potent CSP. Evaluators likely observed errors 


\section{American Journal of Pharmaceutical Education 2019; 83 (9) Article 7338.}
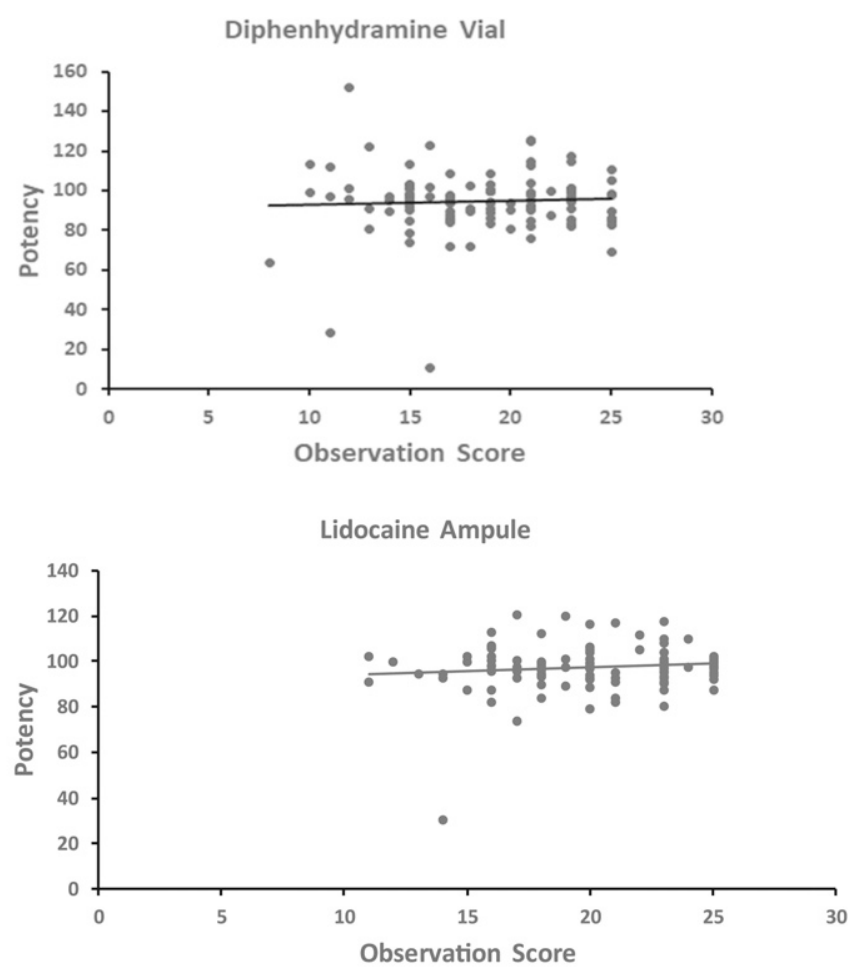

Ampicillin Reconstitution

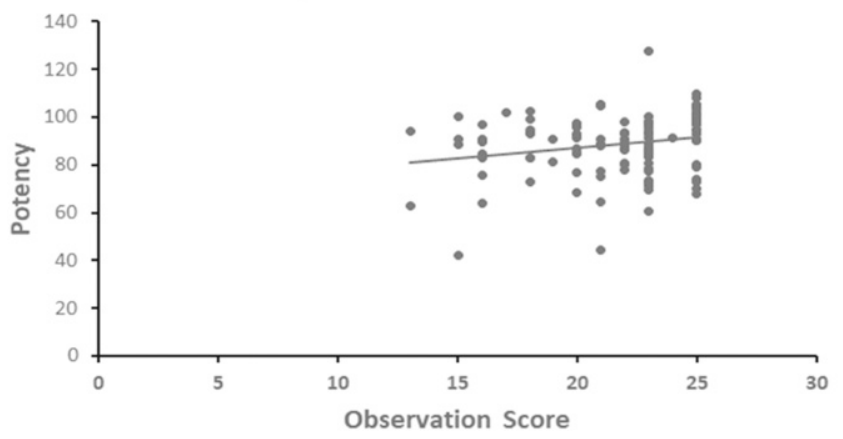

Figure 1. Correlations Between Observational Scores and Potency Values for all Students

in the volume of drug solution withdrawn during the assessment of students. However, prior to this study, the significance of action item 6 was not appreciated in the procedural scheme of the whole encounter.

One specific aspect of volume withdrawal that students found difficult was the pressurization of vials. For the diphenhydramine withdrawal and the ampicillin reconstitution encounters, students had to work with the pull-back pressure within the vial to withdraw the drug solution if the vial was not correctly pressurized. However, the broken ampule was an open system and thus removed the potential for a pull-back pressure on the syringe. During the process of adding normal saline to the ampicillin powder for reconstitution, students may have inadvertently added additional air to the
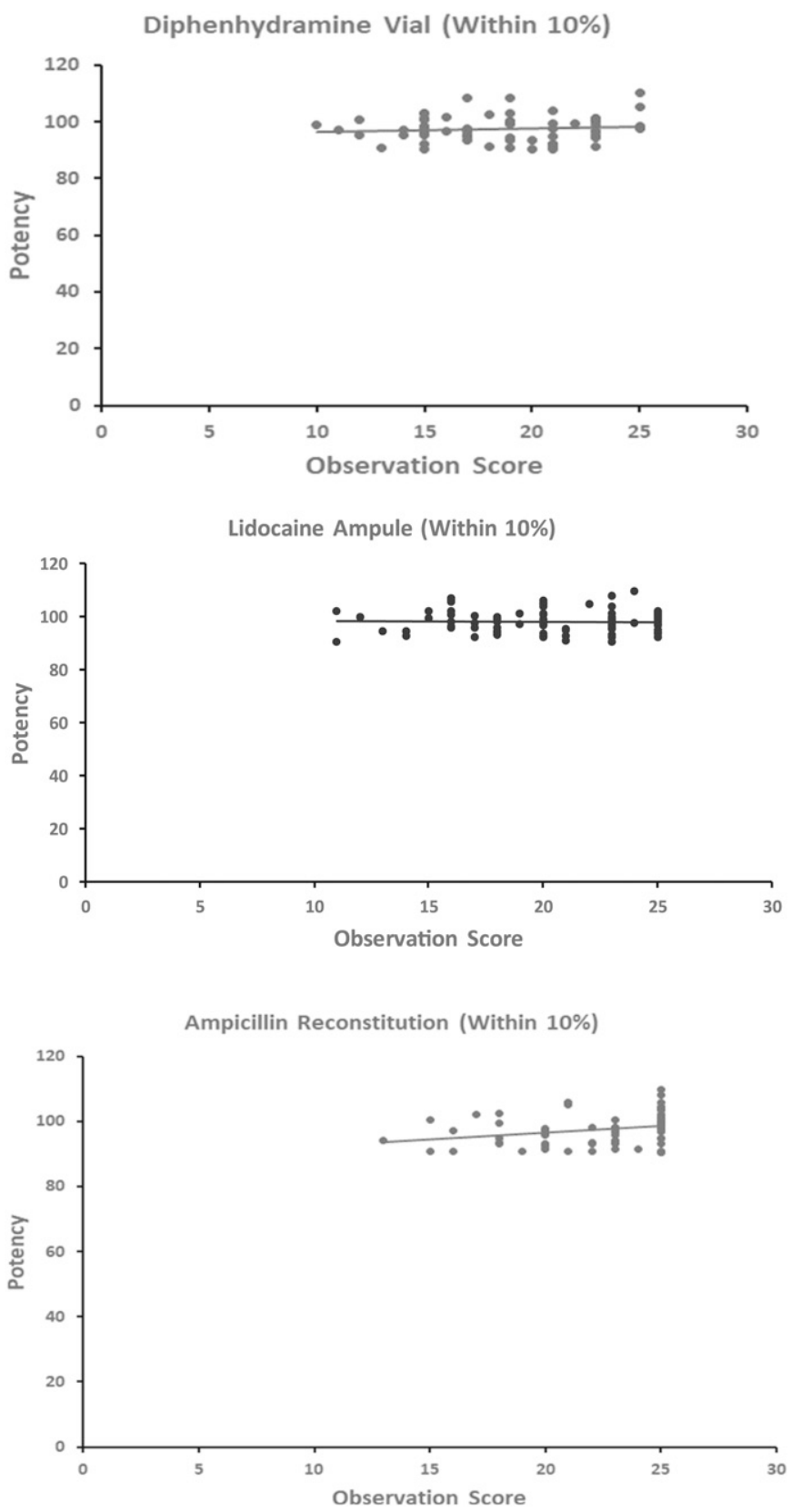

Figure 2. Correlations Between Observational Scores and Potency Values for Students Meeting Potency Endpoint

powder vial or failed to withdraw the same volume of air after adding the diluent, which would have "over pressurized" the vial. Then, when the students again added air to help withdraw the reconstituted ampicillin solution, the vial may have been pressurized even more and created a favorable gradient for the solution to "leak" out of the vial through the hole the needle had made in the vial septum.

The other factor in working with vials that students often fail to appreciate is that the volume of air going into and out of the vial must equal the volume of solution 


\section{American Journal of Pharmaceutical Education 2019; 83 (9) Article 7338.}

Table 5. Correlation Equations of Observational Scores and Potency Values for All Encounters

\begin{tabular}{llc}
\hline Encounter & \multicolumn{1}{c}{ All Students } & Students Meeting Potency Endpoint \\
\hline Diphenhydramine vial & $\mathrm{y}=0.2 \mathrm{x}+90.7, \mathrm{R}^{2}=0.002$ & $\mathrm{y}=0.1 \mathrm{x}+95.4, \mathrm{R}^{2}=0.009$ \\
Lidocaine ampule & $\mathrm{y}=0.3 \mathrm{x}+90.8, \mathrm{R}^{2}=0.01$ & $\mathrm{y}=-0.03 \mathrm{x}+98.7, \mathrm{R}^{2}=0.0005$ \\
Ampicillin reconstitution & $\mathrm{y}=0.9 \mathrm{x}+69.7, \mathrm{R}^{2}=0.04$ & $\mathrm{y}=0.4 \mathrm{x}+88.7, \mathrm{R}^{2}=0.06$ \\
\hline
\end{tabular}

moving into or out of the vial. Many times students will add the appropriate volume of solution into the vial, but will just wait for the syringe plunger to "equalize the air pressure" and then remove the needle-syringe from the vial. Because the plunger equalizes at a smaller air volume than the solution volume that was added, the vial became over pressurized, which again led to the possibility of the preparation "leaking" out of the vial. One approach to avoid this common problem is to use the technique of "milking" the vial in order to avoid the large momentary excesses in air pressurization that typically lead to preparation leakage. This technique repeatedly adds small increments of air to the vial and removes an equivalent small increment of solution. This technique minimizes pressure changes inside the vial while reconstituting the powder with a diluent or removing reconstituted drug solution.

One objective for the course was for students to be able to perform aseptic technique skills at a level that an observer would judge as "appropriate." However, the addition of potency determinations to the aseptic technique encounters indicated that many students could not meet the goal of compounding a preparation that would deliver the right amount of drug to a patient. Potency analysis would not fully examine all aspects of student aseptic technique, but its use does provide additional insight that eludes the limits of visual observation. However, the study indicated that two action items should be added to the observational rubric: verify that the solution volume in the syringe is correct after the removal of air bubbles, and verify that the dosage to be withdrawn is correct.

The authors understand that having laboratories analyze student-compounded preparations as part of the assessment of students' aseptic technical skills would place a significant burden on the course instructor and the school. First, there would be the nominal cost of the additional syringes and needles needed to remove the samples from the CSP IV bags for analysis. In this study, linearity standard curves were used for the spectrophotometric analysis, so standards were prepared that only required a few additional IV bags and vials and ampules. The analysis process for each encounter required an initial development time, but the time to prepare for each encounter's laboratory was minimal. The students analyzed their own preparations, which required that they remove a sample from the IV bag and place the solution into a cuvette, so the analysis time was minimal for students as well.

However, while the observational scores highlighted a specific action item that was a major deficiency in the aseptic technique skills needed to compound acceptable CSPs, the potency analysis provided very critical and specific insights into which manipulative steps were being performed incorrectly. For example, the data clearly demonstrated that students had improved potency when completing the ampule encounter compared to that achieved in the other two encounters, which involved working with pressure inside of vials. The data also reveal that the reconstitution encounter required students to understand that they needed to withdraw an equivalent volume of air from the vial after adding the diluent to avoid problems in subsequent steps because of excess pressure in the vial.

These outcomes showcase the importance of using both observational scores and potency analysis to judge student competency in compounding CSPs. The action item from the observational scores will indicate the difficulty or problem the student is experiencing during the compounding process, and the potency analysis will show how to overcome the difficulty or problem. The synergy of the two assessment methods provides a sound pedagogical approach to ensure compounding competency for students.

\section{REFERENCES}

1. Roark AM, Anksorus HN, Shrewsbury RP. Long-term results of an analytical assessment of student compounded preparations. Am J Pharm Educ. 2014;78(9):Article 164.

2. Accreditation Council for Pharmacy Education. Accreditation standards and guidelines for the professionals program in pharmacy leading to the Doctor of Pharmacy, Standards 2016. https:// www.acpe-accredit.org/pdf/Standards2016FINAL.pdf. Accessed November 12, 2019.

3. Medina MS, Plaza CM, Stowe CD, et al. Center for the Advancement of Pharmacy Education 2013 educational outcomes. Am J Pharm Educ. 2013;77(8):Article 162.

4. Pharmacy Compounding of Sterile Products. https:// nabp.pharmacy/newsroom/news/pharmacy-compounding-of-sterile- 


\section{American Journal of Pharmaceutical Education 2019; 83 (9) Article 7338.}

products-resolution-109-1-13/. Published June 5, 2013. Accessed

November 12, 2019.

5. Nemec EC, Petraglia C, Mattison MJ. Design considerations of a compounded sterile preparations course. Am J Pharm Educ.

2016;80(1):Article 12.

6. Gudeman J, Joziakowski M, Chollet J, Randell M. Potential risks of pharmacy compounding. Drugs R D. 2013 Mar;13(1):1-8.

7. Summary: 2013 FDA Pharmacy Inspection Assignment. http:// www.fda.gov/Drugs/GuidanceComplianceRegulatoryInformation/ PharmacyCompounding/ucm347722.htm. Accessed November 12, 2019. 8. Dennis VC, Owora AH, Kirkpatrick AE. Comparison of aseptic compounding errors before and after modified laboratory and introductory pharmacy practice experiences. Am J Pharm Educ. 2015;79(10):Article 158.

9. Miller CM, Cordova MA, Hladik WB. The status of undergraduate instruction in parenteral products at U.S. colleges of pharmacy. Am J Pharm Educ. 1983;47:48-51.

10. Monk MR, Brown TR, Garner DD, Smith MC. The status of home intravenous therapy instruction provided by U.S. schools and colleges of pharmacy. Am J Pharm Educ. 1991;55(2):120-124. 11. Hellums M, Alverson SP, Monk-Tutor MR. Instruction on compounded sterile preparations at U.S. schools of pharmacy. Am J Health Syst Pharm. 2007;64(21);2267-2274.

12. Brown MC, Conway J, Sorensen TD. Development and implementation of a scoring rubric for aseptic technique. Am J Pharm Educ. 2006;70(6):Article 133.

13. Isanhart CM, McCall KL, Kretschmer D, Grimes BA. Parenterals laboratory course to reduce microbial contamination rates in media fill tests performed by pharmacy students. Am J Pharm Educ. 2008;72(2):Article 27.

14. Ratka A, Demps E, Mack A. The effect of prior experience with aseptic techniques on learning outcomes in a sterile compounding laboratory course. Curr Pharm Teach Learn. 2012;4(1):19-28. 15. Begley K, Monaghan MS, Qi Y. Repeated testing to improve skills in a pharmacy practice laboratory course. Am J Pharm Educ. 2013;77(6): Article 130.

16. Wuller WR, Kwaskborski CL. Developing entry-level competencies in sterile product preparation: an emerging challenge for pharmacy schools and experiential practice sites. Am J Health Syst Pharm. 2012;69(12):1072-1075.

17. Cretton-Scott E, Cruthirds D, Coward L. Incorporation of handson sterile technique instruction in an introductory pharmacy practice experience. Am J Pharm Educ. 2015;79(2):Article 28.

18. Eley JG, Birnie C. Retention of compounding skills among pharmacy students. Am J Pharm Educ. 2006;70(6):Article 132. 19. Neville MW, Palmer R, Elder D, Fulford M, Morris S, Sappington K. Evaluating the effects of flexible learning about aseptic compounding on first-year students in a pharmacy skills laboratory. Am J Pharm Educ. 2015;79(6):Article 91.

20. Patel SP, Vincent AH, Abel SR, Jacobs CM, Dunlop SR, Seibert M. A virtual clean room to teach USP 797 regulations for intravenous medications. Am J Pharm Educ. 2011;75(1):Article 7.

21. Penguin Innovations. https://penguin-innovations.com/.

Accessed November 12, 2019.
22. Martin JA, Regehr G, Reznick R, et al. Objective structured assessment of technical skill (OSATS) for surgical residents. $\mathrm{Br} J$ Surg. 1997;84(2):273-278.

23. Haynes AB, Weiser TG, Berry WR, et al. A surgical safety checklist to reduce morbidity and mortality in a global population. $N$ Engl J Med. 2009;360(5):491-499.

24. Hill JL, Nelson A. New technology, new pedagogy? employing video podcasts in learning and teaching about exotic ecosystems. Environ Educ Res. 2011;17(3):393-408.

25. Abdous M, Facer BR, Yen C-J. Academic effectiveness of podcasting: a comparative study of integrated versus supplemental use of podcasting in second language classes. Comput Educ. 2012;58 (1):43-52.

26. McKinney AA, Page K. Podcasts and video streaming: useful tools to facilitate learning of pathophysiology in undergraduate nurse education? Nurse Educ Pract. 2009;9(6):372-376.

27. Bolliger DU, Supanakorn S, Boggs C. Impact of podcasting on student motivation in the online learning environment. Comput Educ. 2010;55(2):714-722.

28. Traphagan T, Kucsera JV, Kishi K. Impact of class lecture webcasting on attendance and learning. Educ Tech Res Dev.

2010;58(1):19-37.

29. Pierce R, Fox J. Podcasts and active-learning exercises in a 'flipped classroom' model of a renal pharmacotherapy module. Am J Pharm Educ. 2012;76(10):Article 196.

30. Moore WA, Smith AR. Effects of video podcasting on psychomotor and cognitive performance, attitudes and study behavior of student physical therapists. Innovat Educ Teach Int.

2012;49(4):401-414.

31. Schreiber BE, Fukuta J, Gordon F. Live lecture versus video podcast in undergraduate medical education: a randomized controlled trial. BMC Med Educ. 2010;10(1):68.

32. Vogt M, Schaffner B, Ribar A, Chavez R. The impact of podcasting on the learning and satisfaction of undergraduate nursing students. Nurse Educ Pract. 2010;10(1):38-42.

33. Pignato A, Birnie CR. Analysis of compounded pharmaceutical products to teach the importance of quality in an applied pharmaceutics laboratory course. Am J Pharm Educ. 2014;78(3):Article 61.

34. McDowell J, Styles K, Sewell K, et al. A simulated learning environment for teaching medicine dispensing skills. Am J Pharm Educ. 2016;80(1):Article 11.

35. Kosinski TM, Brown MC, Valdovinos K, Zavala PJ. Acquisition and retention of sterile compounding accuracy skills. Am J Pharm Educ. 2017;81(6):Article 115.

36. Shrewsbury R, Augustine S, Birnie C, et al. Assessment and recommendations of compounding education in AACP member institutions. Am J Pharm Educ. 2012;76(7):Article S9.

37. Alford EL, Shrewsbury RP. Impact of required versus optional remake of a preparation on pharmacy students' compounding accuracy. Am J Pharm Educ. 2013;77(4):Article 73.

38. Jih JS, Shrewsbury RP. Student self-analysis of their nonsterile preparations and its effect on compounding confidence. Am J Pharm Educ. 2018;82(10):Article 6473. 


\section{American Journal of Pharmaceutical Education 2019; 83 (9) Article 7338.}

Appendix 1. Observational Rubric Used in the First (Vial) Encounter

\begin{tabular}{ll}
\hline Value & Action \\
\hline 2 & Performs all operations at least 6" inside the LAFW and 3" from the back of the LAFW. \\
2 & Assembles necessary supplies; syringe and needle sizes are appropriate to task. \\
2 & Arranges items in LAFW such that nothing comes between the HEPA filter and the sterile items. Avoids \\
& extraneous items in LAFW. \\
& Swabs all septa and injection ports with alcohol pads. One wipe with one pad for each septa and port. Swipe from \\
& filter side toward the compounder. \\
& Opens syringe and attaches needle within LAFW. Opens by peeling paper, not "punching" syringe/needle through \\
& paper. Does not touch needle, syringe tip, or stem of plunger. \\
& Withdraws contents of vial or glass ampule appropriately (see additional guidelines if needed). \\
& Remembers to swab all puncture surfaces prior to using. \\
& Removes air bubbles from syringe and avoids touching needle, syringe tip or plunger stem. \\
& If glass ampule, filters solution while withdrawing and changes needle before transferring to bag. \\
& Protects critical sites by not blocking first air. \\
& Withdraws correct volume of solution from ampule or vial. \\
& Transfers solution into bag appropriately: inserts needle at appropriate angle (angled with bevel up for bag top \\
& ports; straight through port for bag end ports) and checks to make sure needle delivers medication into bag and \\
& not into intra-septal space. \\
& Inspects the solution for particles (best if against both light and dark backgrounds) and shakes bag to ensure mixing \\
& of solution. \\
& Disposes of materials appropriately (needles in sharps container; syringe, paper, alcohol wipes, etc., in trash \\
& container)
\end{tabular}

Abbreviations: LAFW: Laminar Air Flow Workbench. HEPA filter: High-efficiency Particulate Air filter

Appendix 2. Observational Rubric Used With Second (Ampule) and Third (Reconstitution) Encounters

\begin{tabular}{ll}
\hline Value & Action \\
\hline 3 & Performs all operations at least 6" inside the LAFW and 3" from the back of the LAFW. \\
2 & Assembles necessary supplies; syringe and needle sizes are appropriate to task. \\
2 & Arranges items in LAFW such that nothing comes between the HEPA filter and the sterile items. Avoids \\
& extraneous items in LAFW. \\
& Swabs all septa, puncture surfaces, and injection ports with alcohol pads. Wipe should be from filter side toward \\
& the compounder. Single swab per each item, and a single swipe per each item. \\
& Opens syringe and attaches needle within LAFW. Opens by peeling paper, not "punching" syringe/needle through \\
& paper. Does not touch needle, syringe tip, or stem of plunger. \\
& Withdraws contents of vial or glass ampule appropriately. \\
& Removes air bubbles from syringe and avoids touching needle, syringe tip or plunger stem. \\
& If glass ampule, filters solution while withdrawing and changes needle before removing air and transferring to bag. \\
& The correct volume is withdrawn from the ampule or vial. \\
& Transfers solution into bag appropriately: inserts needle at appropriate angle (angled with bevel up for bag top \\
& ports; straight through port for bag end ports) and checks to make sure needle delivers medication into bag and \\
& not into intra-septal space. \\
& Inspects the solution for particles (best if against both light and dark backgrounds) and shakes bag to ensure mixing \\
& of solution. \\
& Disposes of materials appropriately (needles in sharps container; syringe in trash). Disposes of additional materials \\
& (paper, alcohol wipes, etc.) in general waste disposal containers.
\end{tabular}

Abbreviations: LAFW: Laminar Air Flow Workbench. HEPA filter: High-efficiency Particulate Air filter 